\title{
Calcitriol Suppression of Parathyroid Hormone Fails to Improve Skeletal Properties in an Animal Model of Chronic Kidney Disease
}

\author{
Christopher L. Newman ${ }^{b}$ Nannan Tian ${ }^{a}$ Max A. Hammond ${ }^{d}$ \\ Joseph M. Wallace c,d Drew M. Brown ${ }^{b}$ Neal X. Chen ${ }^{d}$ Sharon M. Moe ${ }^{d, e}$ \\ Matthew R. Allen ${ }^{b-d}$ \\ a Materials Engineering, Purdue University, Weldon School of Biomedical Engineering, Purdue University, \\ West Lafayatte, ${ }^{b}$ Department of Anatomy and Cell Biology, Indiana University School of Medicine, ${ }^{\circ}$ Department of \\ Biomedical Engineering, Indiana University - Purdue University, ${ }^{\mathrm{d}}$ Department of Medicine, Division of Nephrology

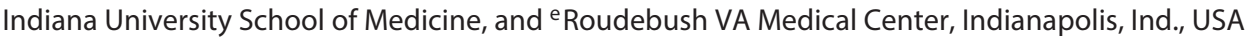

\section{Key Words}

Animal models · Bone disease - Chronic kidney disease .

Treatment $\cdot$ Calcitriol

\begin{abstract}
Background: Chronic kidney disease (CKD) leads to complex metabolic changes and an increased risk of fracture. Current$l y$, calcitriol is the standard of care as it effectively suppresses parathyroid hormone (PTH) levels in CKD patients. While calcitriol and its analogs improve BMD and reduce fractures in the general population, the extension of these benefits to patients with advanced kidney disease is unclear. Here, the impact of calcitriol on the skeleton was examined in the setting of reduction in PTH. Methods: Male Cy/+ rats, a PKD-like CKD model, were treated with either vehicle or calcitriol for 5 weeks. Their normal littermates served as controls. Animals were assessed for changes in mineral metabolism and skeletal parameters (microCT, histology, whole bone mechanics and bone quality). Results: PTH levels were significantly higher (12-fold) in animals with CKD compared to normal controls. CKD animals also exhibited negative changes in bone structural and mechanical properties. Calcitriol treatment resulted in a $60 \%$ suppression of PTH levels in animals with CKD. Despite these changes, it had no impact on bone
\end{abstract}

volume (cortical or cancellous), bone turnover, osteoclast number or whole bone mechanical properties. Conclusions: These data indicate that while calcitriol effectively lowered PTH in rats with CKD, it did little to prevent the negative effects of secondary hyperparathyroidism on the skeleton.

(c) 2016 S. Karger AG, Basel

\section{Introduction}

Chronic kidney disease-mineral and bone disorder (CKD-MBD) represents a conglomeration of various metabolic and skeletal changes, such as hyperphosphatemia, secondary hyperparathyroidism and an increased fracture risk [1-3]. Currently, the primary goal of therapy is the suppression of elevated levels of parathyroid hormone (PTH) [4]. For FDA approval, the standard end point for the treatment of secondary hyperparathyroidism has been a reduction of PTH by $30 \%$ or more $[5,6]$. Due to a paucity of data (detailed in the kidney disease improving global outcomes guidelines), the impact of these levels of suppression on vascular and skeletal outcomes is unclear $[3,7,8]$.

Though imperfect, serum PTH is considered a surrogate biomarker for underlying renal osteodystrophy [9-11].

\section{KARGER}

E-Mail karger@karger.com

www.karger.com/ajn
(C) 2016 S. Karger AG, Basel

0250-8095/16/0431-0020\$39.50/0 
Calcitriol, vitamin D analogs and calcimimetics all lower PTH, but data that assess their efficacy on bone are rather limited. While most osteoporosis clinical studies in nonCKD patients demonstrate that calcitriol reduces fracture risk through improvements in BMD $[12,13]$, the extension of these benefits to patients with advanced kidney disease where cortical bone is adversely affected is unclear [4]. Preclinical studies using calcium to suppress PTH to normal (or below) levels largely preserves skeletal properties [1417]. Unfortunately, this effectiveness comes at the cost of increased vascular calcification, at least when hypercalcemia ensues. These data are consistent with concerns raised in CKD patients about the use of calcium supplementation and calcium-based phosphate binders [18-23].

In light of these data, a more thorough examination of the effects of calcitriol therapy on specific skeletal outcomes seems warranted. Despite widespread use clinically, there are limited calcitriol intervention studies in humans and animal models that examine tissue properties (histomorphometry, trabecular architecture, cortical geometry, etc.). Fracture prevention studies have not been conducted for calcitriol in patients with CKD, and limited preclinical studies have evaluated mechanical properties of bone with intervention. The goal of the current study was to fill these voids in a preclinical model of CKD. Specifically, we sought to investigate how suppression of PTH levels with calcitriol would impact skeletal properties using an animal model of progressive CKD.

\section{Methods}

\section{Animal Model}

$\mathrm{Cy} /+$ rats are characterized by autosomal dominant cystic disease [24]. These animals have a mutation (R823W) in Anks6, a gene that codes for the protein SamCystin. The exact function of this protein is unknown [25], but unlike many other cyst-related proteins, SamCystin does not localize to the primary cilia of kidney cells [26]. Recently, this gene was shown to be responsible for nephronophthisis in humans [27]. In this rat model, the mutation leads to a slow and gradual onset of CKD [24]. It parallels the human condition through the progressive development of hyperphosphatemia, secondary hyperparathyroidism and vascular calcification. Blood urea nitrogen (BUN) and creatinine are elevated by 20 weeks of age. Skeletal abnormalities consistent with osteitis fibrosa cystica are present by 30 weeks.

\section{Experimental Design}

At 24 weeks, male $\mathrm{Cy} /+$ rats were placed on a casein diet $(\mathrm{Pu}-$ rina $\mathrm{AIN}-76 \mathrm{~A} ; 0.7 \% \mathrm{Pi}, 0.6 \% \mathrm{Ca}$ ), which we have shown to produce a more consistent kidney disease phenotype [24]. At this point, these animals have reached their full adult weights. Starting at 25 weeks of age, $\mathrm{Cy} /+$ rats were treated with vehicle $(\mathrm{n}=9)$ or calcitriol ( $\mathrm{n}=11 ; 10 \mathrm{ng} / \mathrm{kg} 3 \times$ weekly; intraperitoneal) for 5 weeks.
This treatment duration was chosen as it approximates an average bone remodeling cycle in skeletally mature rats (roughly 6 months in humans) and has been shown to be sufficient to detect treatment-induced skeletal changes in this model $[28,29]$. Based on preliminary studies in these animals, calcitriol doses were chosen to achieve approximately $50 \%$ suppression of PTH levels. Nonaffected male littermates served as controls $(n=8)$. All rats were injected with calcein (10 mg/kg; subcutaneous) 14 and 4 days prior to sacrifice to label surfaces with active bone formation.

At 30 weeks of age, animals were anesthetized with isoflurane and underwent cardiac puncture for blood draw followed by exsanguination and bilateral pneumothorax to ensure death. The lumbar spine, tibiae and femora were removed and stored at $-20^{\circ} \mathrm{C}$ for analysis. All procedures were approved by and carried out according to the rules and regulations of the Indiana University School of Medicine's Institutional Animal Care and Use Committee. Some of the data from normal and CKD-VEH animals have been published previously as these control groups were part of a larger study of which calcitriol treatment was one sub-group [54].

\section{Biochemistry}

Blood plasma at 30 weeks was analyzed for BUN, calcium and phosphorus using colorimetric assays (Point Scientific, Sigma kits, Canton, M.I., USA). Intact PTH was determined by ELISA (Alpco, Salem, N.H., USA).

\section{MicroCT}

Using microCT (Skyscan 1172), trabecular architecture was determined from the metaphysis of the proximal tibia and the full length of the L4 vertebra. Cortical bone geometry was determined from the femoral midshaft. Cortical thickness (Ct.Th) was assessed at $75 \%$ of the height of the vertebra (from cranial to caudal) because this represents a region free of zygapophyseal attachment. All bones were wrapped in parafilm to prevent drying and scanned at a resolution of $12 \mu \mathrm{m}$ in accordance with standard guidelines [30].

\section{Histomorphometry}

Static and dynamic histomorphometric measures were obtained from the proximal metaphysis of the tibia as well as the caudal metaphysis of the L 3 vertebra. Histological processing followed previously used protocols from this lab [31-33]. Tissues were embedded in methyl methacrylate for undecalcified sections. Transverse sections from the proximal tibia and frontal sections from the caudal portion of the L3 vertebra were cut and left unstained for dynamic histomorphometry or stained with tartrate-resistant acid phosphatase (TRAP) for osteoclast measurements (tibia only). For cancellous bone, a region of interest that was approximately $0.8 \mathrm{~mm}$ from the growth plate was analyzed. Unstained sections were assessed for total bone surface (BS), single-labeled surface and double-labeled surface to calculate mineral apposition rate (MAR), percent mineralizing surface (MS)/BS and bone formation rate (BFR)/BS. TRAP-stained sections were assessed for $\mathrm{BS}$, osteoclast number and osteoclast surface (Oc.S) to calculate the number of osteoclasts per unit BS and percent Oc.S/BS. All histomorphometric nomenclature follows standard usage [34].

\section{Whole Bone Mechanics}

Structural mechanical properties of femora were determined by 4 -point bending. The anterior surface was placed on 2 lower supports located $\pm 9 \mathrm{~mm}$ from the mid-diaphysis (18 $\mathrm{mm}$ span 
Table 1. Biochemical profiles of animals at 30 weeks of age

\begin{tabular}{lccc}
\hline & Normal & CKD (vehicle) & CKD (calcitriol) \\
\hline BUN, mg/dl & $14.62 \pm 1.95$ & $48.32 \pm 8.20^{*}$ & $43.01 \pm 7.07^{*}$ \\
Calcium, mg/dl & $9.979 \pm 0.987$ & $11.610 \pm 2.323$ & $10.240 \pm 1.872$ \\
Phosphorus, mg/dl & $4.527 \pm 0.579$ & $6.682 \pm 2.408^{*}$ & $7.776 \pm 1.170^{*}$ \\
PTH, pg/ml & $181.97 \pm 105.05$ & $2,194.39 \pm 1,811.01^{*}$ & $875.12 \pm 432.51^{*}, \#$ \\
\hline
\end{tabular}

* vs. normal; ${ }^{\#}$ vs. CKD (vehicle). BUN = Blood urea nitrogen; PTH = parathyroid hormone.

length) with an upper span length of $6 \mathrm{~mm}$. Specimens were loaded to failure at a rate of $2 \mathrm{~mm} / \mathrm{min}$. Structural mechanical properties were obtained directly from the force-displacement curves, while apparent material properties were derived from the forcedisplacement curves, cross-sectional moments of inertia and the distances from the centroid to the tensile surface using standard beam bending equations for 4-point bending [35].

Structural mechanical properties of L4 vertebrae were determined by uniaxial compression. Vertebra height was assessed from microCT images. Prior to mechanical testing, the vertebral arch and end plates were removed to create parallel surfaces for compression testing. Specimens were loaded at a rate of $0.5 \mathrm{~mm} / \mathrm{min}$. Structural mechanical properties were obtained directly from the force-displacement curves, while apparent material properties were derived from the force-displacement curves, pre-test sample heights and the average bone area of 5 microCT slices $(10,30,50$, 70 and $90 \%$ slices of the pre-test sample height) using equations for uniaxial compression $[36,37]$.

\section{Tissue Composition}

The anteromedial portion of the tibial mid-diaphysis was polished with a $0.05 \mu \mathrm{m}$ alumina suspension in order to create a flat region for spectroscopy and indentation testing. Composition was assessed using a LabRAM HR 800 Raman Spectrometer (HORIBA JobinYvon, Edison, N.J., USA). A $660 \mathrm{~nm}$ laser was focused on the BS using a $50 \mathrm{X}$ objective to a spot size of $\sim 10 \mu \mathrm{m}$. Three locations were imaged $\sim 3 \mathrm{~mm}$ apart with $520 \mathrm{~s}$ acquisitions at each location as previously published [38]. A 5-point linear baseline correction was applied in LabSpec 5 (HORIBA JobinYvon). Using OriginPro 8.6 (OriginLab, Northampton, Mass., USA), a single Gaussian peak was fit to the $\mathrm{PO}_{4}{ }^{3-} v 1$ peak, and the areas under the $\mathrm{PO}_{4}{ }^{3-} v 1$, $\mathrm{CO}_{3}{ }^{2-} v 1$ and Amide I peaks were calculated at each location. Type $\mathrm{B}$ carbonate substitution was found by the band area ratio of $\mathrm{CO}_{3}{ }^{2-}$ $v 1 / \mathrm{PO}_{4}{ }^{3-} v 1$. The degree of matrix mineralization was determined by the band area ratio of $\mathrm{PO}_{4}{ }^{3-} v 1 /$ Amide I. Mineral maturity (crystallinity) was determined by the inverse of the full width at half maximum of the $\mathrm{PO}_{4}{ }^{3-} v 1$ peak.

\section{Nanoindentation}

After Raman spectroscopy, nanoindentation was performed on the same samples using a Hysitron TI 950 TriboIndenter. Samples were partially submerged in ultrapure water with the surface remaining uncovered for optical imaging of the surface to determine indentation locations but then fully submerged during testing. Locations were imaged using in situ scanning probe imaging. Then, 6 indentations were performed on a $10 \times 20 \mu \mathrm{m}$ grid, avoiding interactions from neighboring indentations. A previously calibrated fluid cell Berkovich diamond probe was used for the indentations. Machine calibrations were performed at the beginning of each day of testing. Tests were conducted in load control with a $10 \mathrm{~s}$ loading period, a $10 \mathrm{~s}$ hold at $3,000 \mu \mathrm{N}$ and a $10 \mathrm{~s}$ unloading period. From the resulting load-displacement profiles, the indentation elastic modulus and hardness were calculated according to the following equations:

$$
\begin{aligned}
& \mathrm{E}_{\mathrm{r}}=\frac{\sqrt{\pi}}{2 \sqrt{\mathrm{A}\left(\mathrm{h}_{\mathrm{c}}\right)}} \cdot \mathrm{S} \\
& \mathrm{H}=\frac{\mathrm{P}_{\max }}{\mathrm{A}\left(\mathrm{h}_{\mathrm{c}}\right)}
\end{aligned}
$$

where $\mathrm{E}_{\mathrm{r}}$ is the reduced indentation elastic modulus of the sample, $A$ is contact area, $\mathrm{h}_{\mathrm{c}}$ is the contact displacement, $\mathrm{S}$ is the stiffness of the sample determined from 40 to $95 \%$ of the unloading slope, $\mathrm{H}$ is the hardness of the sample and $\mathrm{P}_{\max }$ is the peak force. All of the individual indentations ( $n=6$ per location) were averaged to produce a single value for each location, and each of these locations was averaged to produce a single value for each sample.

\section{Statistics}

Comparisons among groups were assessed by one-way analysis of variance with Fisher's LSD post-hoc tests. A priori a-levels were set at 0.05 to determine significance.

\section{Results}

\section{Mineral Metabolism}

Animals with CKD had higher serum levels of BUN compared to normal littermates. Serum calcium was normal, while phosphorus and PTH levels were significantly higher than their normal counterparts (table 1). Animals treated with calcitriol had BUN, calcium and phosphorus values similar to their untreated CKD counterparts. PTH levels in calcitriol animals were significantly lower than in untreated CKD animals (-61\%) but still higher than in normal controls $(+381 \%)$. 
Fig. 1. Cancellous bone structure in the proximal tibia and lumbar vertebra as determined by microCT. ${ }^{*} \mathrm{p}<0.05$ compared to NL.

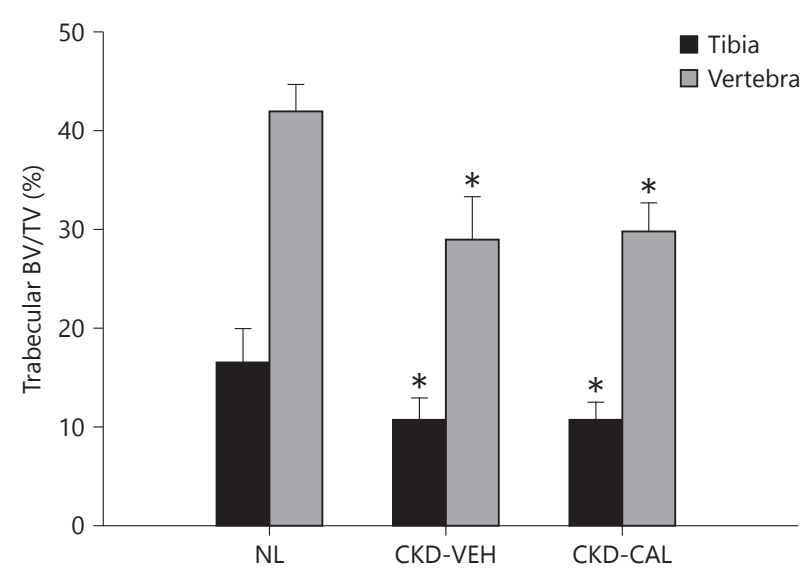

Table 2. Bone architecture and geometry of long bones and vertebra

\begin{tabular}{|c|c|c|c|}
\hline Proximal tibia & Normal & CKD (vehicle) & CKD (calcitriol) \\
\hline BV/TV, \% & $17.04 \pm 3.34$ & $11.26 \pm 1.51^{*}$ & $10.70 \pm 1.77 *$ \\
\hline Tb.Th, mm & $0.106 \pm 0.010$ & $0.108 \pm 0.004$ & $0.101 \pm 0.005^{*}$ \\
\hline Tb.N, 1/mm & $1.611 \pm 0.253$ & $1.052 \pm 0.150^{*}$ & $1.057 \pm 0.163^{*}$ \\
\hline $\mathrm{Tb} . \mathrm{Sp}, \mathrm{mm}$ & $0.369 \pm 0.044$ & $0.604 \pm 0.114^{*}$ & $0.523 \pm 0.084^{*}$ \\
\hline \multicolumn{4}{|c|}{ Femoral diaphysis } \\
\hline Ct.Th, mm & $0.876 \pm 0.037$ & $0.748 \pm 0.056^{*}$ & $0.769 \pm 0.045^{*}$ \\
\hline Ct.Ar, mm ${ }^{2}$ & $8.767 \pm 0.631$ & $7.324 \pm 0.358^{*}$ & $7.647 \pm 0.378^{*}$ \\
\hline $\mathrm{I}_{\mathrm{ap}}, \mathrm{mm}^{4}$ & $15.00 \pm 2.59$ & $12.40 \pm 0.58^{*}$ & $13.19 \pm 0.89^{*}$ \\
\hline $\mathrm{I}_{\mathrm{ml}}, \mathrm{mm}^{4}$ & $10.23 \pm 1.56$ & $7.50 \pm 0.59 *$ & $8.30 \pm 0.99 *$ \\
\hline Ct.Po, \% & $0.690 \pm 0.324$ & $0.948 \pm 0.401$ & $0.769 \pm 0.377$ \\
\hline \multicolumn{4}{|c|}{ Lumbar vertebra } \\
\hline BV/TV, \% & $41.88 \pm 2.92$ & $30.01 \pm 3.98^{*}$ & $29.83 \pm 2.88^{*}$ \\
\hline Tb.Th, mm & $0.119 \pm 0.004$ & $0.110 \pm 0.007^{*}$ & $0.105 \pm 0.008^{*}$ \\
\hline Tb.N, 1/mm & $3.581 \pm 0.258$ & $2.726 \pm 0.324^{*}$ & $2.823 \pm 0.220^{*}$ \\
\hline Tb.Sp, mm & $0.213 \pm 0.021$ & $0.280 \pm 0.031^{*}$ & $0.275 \pm 0.018^{*}$ \\
\hline Ct.Th, mm & $0.236 \pm 0.033$ & $0.170 \pm 0.012^{*}$ & $0.191 \pm 0.035^{*}$ \\
\hline
\end{tabular}

* vs. normal; ${ }^{\#}$ vs. CKD (vehicle).

$\mathrm{BV} / \mathrm{TV}=$ Bone volume/tissue volume; Tb.Th = trabecular thickness; Tb. $\mathrm{N}=$ trabecular number; $\mathrm{Tb} . \mathrm{Sp}=$ trabecular spacing; $\mathrm{I}_{\mathrm{ap}}=$ moment of inertia in the anterior-posterior direction; $\mathrm{I}_{\mathrm{ml}}=$ moment of inertia in the medial lateral direction; Ct.Po = cortical porosity.

\section{MicroCT}

Vehicle-treated CKD animals had lower trabecular bone volume than normal animals at the proximal tibia. A similar pattern was observed in the vertebra. In both cases, animals treated with calcitriol displayed no differences than their CKD vehicle counterparts (fig. 1 and table 2). All other trabecular parameters were similar between calcitriol animals and the untreated CKD animals.

Calcitriol Fails to Improve Bone in CKD Animals
Cortical bone of the femoral midshaft and lumbar vertebra was also negatively affected by CKD. CKD animals had lower cortical area (Ct.Ar), Ct.Th and bending moments of inertia compared to those of normal controls (table 2). Animals treated with calcitriol displayed cortical values similar to CKD vehicle animals. Calcitriol did not correct CKD-induced changes in Ct.Ar, thickness, porosity or polar moment of inertia of the femur or Ct.Th of the vertebra (table 2 ). 
Fig. 2. BFRs in the proximal tibia and caudal lumbar vertebra as determined by dynamic histomorphometry. ${ }^{*} \mathrm{p}<0.05 \mathrm{com}-$ pared to NL.

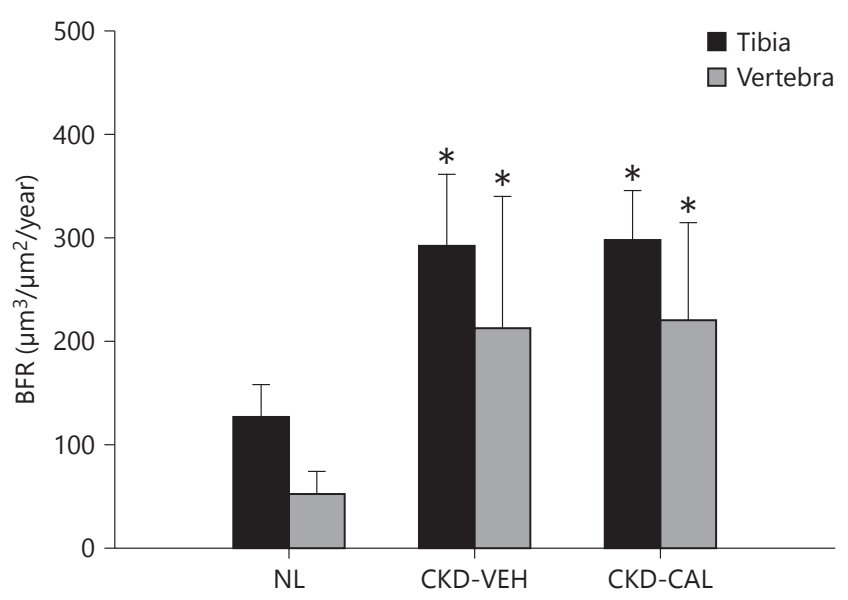

Table 3. Trabecular bone histomorphometry

\begin{tabular}{lccc}
\hline Tibia & Normal & CKD (vehicle) & CKD (calcitriol) \\
\hline MAR, $\mu \mathrm{m} /$ day & $1.305 \pm 0.185$ & $2.470 \pm 0.569^{*}$ & $2.285 \pm 0.343^{*}$ \\
MS/BS, \% & $26.56 \pm 5.14$ & $33.32 \pm 4.11$ & $35.86 \pm 3.26^{*}, \#$ \\
BFR/BS, $\mu \mathrm{m}^{3} / \mu \mathrm{m}^{2} /$ year & $126.65 \pm 31.02$ & $299.62 \pm 74.35^{*}$ & $298.51 \pm 47.41^{*}$ \\
Oc.S/BS, \% & $7.157 \pm 1.250$ & $15.739 \pm 3.332^{*}$ & $13.538 \pm 2.790^{*}$ \\
N.Oc/BS, $/ \mathrm{mm}$ & $1.966 \pm 0.412$ & $4.125 \pm 0.785^{*}$ & $3.604 \pm 0.590^{*}$ \\
\hline Vertebra & & & \\
MAR, $\mu \mathrm{m} /$ day & $1.057 \pm 0.339$ & $1.983 \pm 0.876^{*}$ & $1.87 \pm 0.52^{*}$ \\
$\mathrm{MS} / \mathrm{BS}, \%$ & $13.62 \pm 3.98$ & $27.81 \pm 5.73^{*}$ & $31.39 \pm 4.58^{*}$ \\
$\mathrm{BFR} / \mathrm{BS}, \mu \mathrm{m}^{3} / \mu \mathrm{m}^{2} /$ year & $52.14 \pm 21.76$ & $211.94 \pm 128.49^{*}$ & $220.61 \pm 94.32^{*}$ \\
\hline
\end{tabular}

* vs. normal; " vs. CKD (vehicle).

$\mathrm{MAR}=$ Mineral apposition rate; $\mathrm{MS} / \mathrm{BS}=$ mineralizing surface/bone surface; $\mathrm{BFR} / \mathrm{BS}=$ bone formation rate per bone surface; Oc.S/BS = osteoclast surface per bone surface; N.Oc/BS = number of osteoclasts per bone surface.

\section{Histology}

Vehicle-treated CKD animals had higher trabecular BFRs in the tibia and vertebra as well as higher osteoclast number and percent Oc.S than their normal counterparts (fig. 2 and table 3). Calcitriol animals displayed similar values to $\mathrm{CKD}$ vehicle animals with regard to MAR, osteoclast number and percent Oc.S. While animals with calcitriol had a slightly higher proportion of MS than CKD vehicle animals (in the tibia only), BFRs at both sites were similar between these groups.

\section{Whole Bone Mechanics}

Animals with CKD had lower femoral ultimate force, stiffness and energy to fracture compared to normal animals (fig. 3 and table 4). Estimated material properties re- vealed a significantly lower modulus of toughness in CKD animals (fig. 3) with no differences in the ultimate stress or elastic modulus (table 4). Animals treated with calcitriol displayed no treatment effects compared to vehicle-treated CKD. They were similar with regard to ultimate force, stiffness and energy to fracture (fig. 3). Calcitriol treatment also had no effect on estimated material properties (table 4).

Vertebral compression tests, which assess both trabecular and cortical bone, revealed that CKD animals had lower ultimate force and energy to ultimate force but no differences in stiffness compared to normal animals (fig. 3). Estimated material properties were similar among all 3 groups. As above, vertebrae from calcitriol animals were no different from their untreated CKD counterparts. 


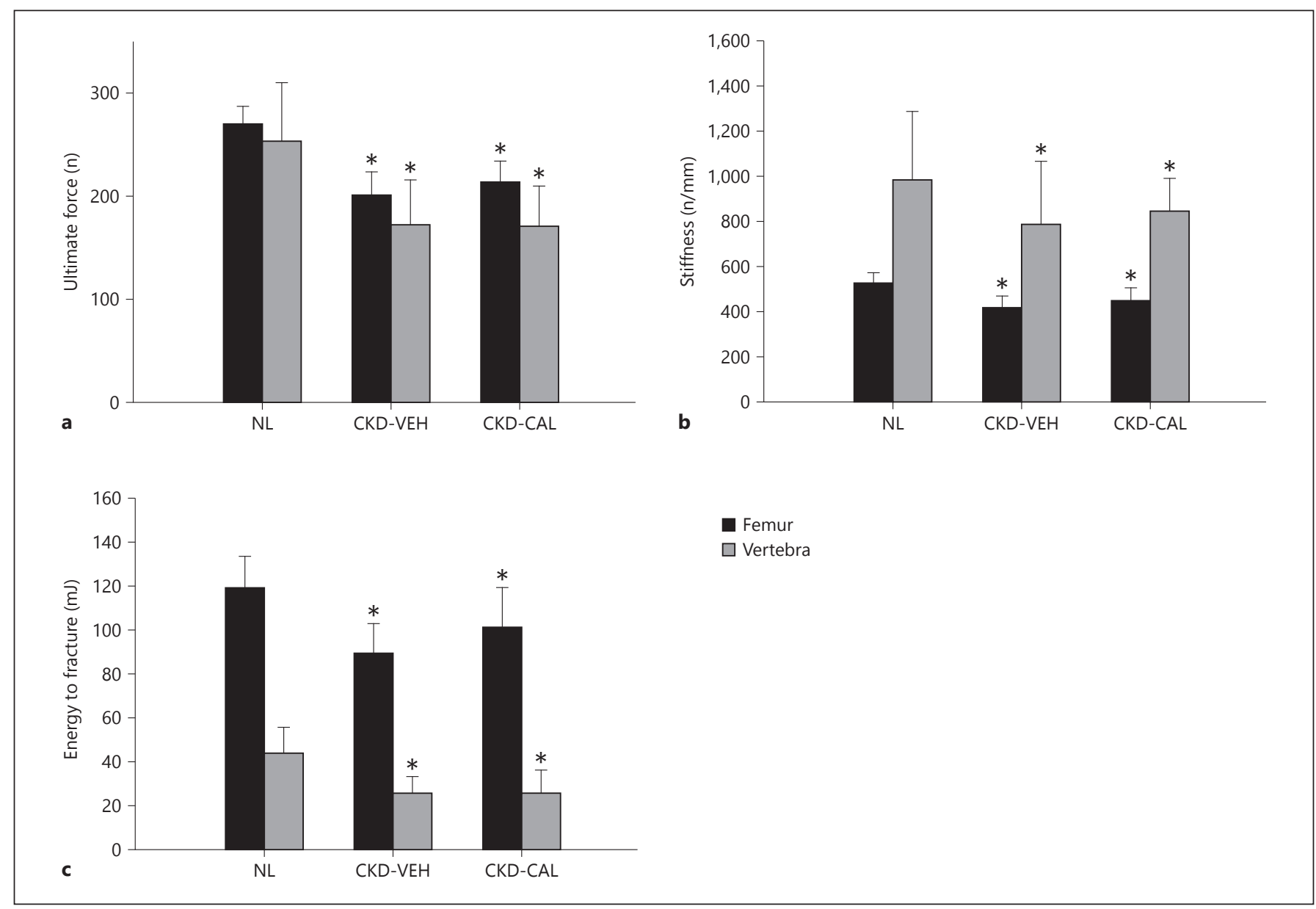

Fig. 3. Whole bone mechanical properties of the femur as determined by 4-point bending: (a) ultimate load, (b) stiffness and (c) energy to fracture. ${ }^{*} \mathrm{p}<0.05$ compared to NL.

Table 4. Structural and material mechanical properties

\begin{tabular}{lccc}
\hline & Normal & CKD (vehicle) & CKD (calcitriol) \\
\hline Femur & & & \\
Ultimate force, $\mathrm{n}$ & $272.08 \pm 17.75$ & $204.81 \pm 23.20^{*}$ & $214.00 \pm 20.04^{*}$ \\
Stiffness, n/mm & $531.67 \pm 47.41$ & $412.96 \pm 56.28^{*}$ & $446.99 \pm 58.57^{*}$ \\
Energy to fracture, mJ & $119.16 \pm 15.33$ & $91.65 \pm 14.13^{*}$ & $101.305 \pm 17.98^{*}$ \\
Ultimate stress, MPa & $153.81 \pm 15.68$ & $143.94 \pm 17.93$ & $136.49 \pm 9.60$ \\
Elastic modulus, MPa & $4.649 \pm 0.633$ & $5.144 \pm 0.971$ & $4.830 \pm 0.696$ \\
Toughness, MPa & $4.336 \pm 0.382$ & $3.652 \pm 0.545^{*}$ & $3.815 \pm 0.518^{*}$ \\
\hline Vertebra & & & $171.31 \pm 38.19^{*}$ \\
Ultimate force, n & $256.89 \pm 60.01$ & $187.06 \pm 48.03^{*}$ & $845.67 \pm 144.32$ \\
Stiffness, $\mathrm{n} / \mathrm{mm}$ & $952.09 \pm 314.20$ & $866.74 \pm 260.33$ & $25.38 \pm 10.88^{*}$ \\
Energy, mJ & $46.27 \pm 10.60$ & $28.05 \pm 8.93^{*}$ & $35.33 \pm 10.88$ \\
Ultimate stress, MPa & $42.49 \pm 10.00$ & $38.74 \pm 9.16$ & $1,131.84 \pm 170.17$ \\
Elastic modulus, MPa & $954.37 \pm 334.35$ & $1,174.00 \pm 447.08$ & $0.819 \pm 0.386$ \\
Toughness, MPa & $1.310 \pm 0.470$ & $0.924 \pm 0.347$ & \\
\hline
\end{tabular}

* vs. normal. 
Table 5. Bone quality

\begin{tabular}{lccc}
\hline & Normal & CKD (vehicle) & CKD (calcitriol) \\
\hline Raman spectroscopy & & & \\
$\quad$ Crystallinity (1/FWHM $\left.\mathrm{PO}_{4}{ }^{3-} v 1\right)$ & $0.0529 \pm 0.0003$ & $0.0534 \pm 0.0008$ & $0.0534 \pm 0.0004$ \\
$\quad$ Carbonate substitution $\left(\mathrm{CO}_{3}{ }^{2-} v 1 / \mathrm{PO}_{4}{ }^{3-} v 1\right)$ & $0.247 \pm 0.008$ & $0.242 \pm 0.013$ & $0.238 \pm 0.013$ \\
$\quad$ Relative mineralization $\left(\mathrm{PO}_{4}{ }^{3-} v 1 / \mathrm{Amide} \mathrm{I}\right)$ & $2.598 \pm 0.341$ & $2.403 \pm 0.442$ & $2.759 \pm 0.299$ \\
Nanoindentation & & & \\
$\quad$ Elastic modulus, GPa & $11.066 \pm 2.766$ & $9.666 \pm 1.021$ & $9.987 \pm 2.610$ \\
$\quad$ Hardness, MPa & $202.62 \pm 22.86$ & $192.68 \pm 47.35$ & $209.426 \pm 43.65$ \\
\hline
\end{tabular}

\section{Bone Quality}

Compared to normal controls, animals with CKD were found to have no differences in indentation properties. Calcitriol had no effect on these properties either (table 5). Tissue composition assessed by Raman spectroscopy revealed no differences in any of the compositional parameters among the groups either.

\section{Discussion}

The goal of this study was to assess the impact of PTH suppression on CKD-induced bone disease. Using calcitriol, the current standard of care in patients with secondary hyperparathyroidism, PTH levels were suppressed by $60 \%$ in animals with CKD. Despite this reduction, no skeletal benefits were observed. This is likely in part due to the failure of calcitriol to suppress BFRs and osteoclast formation, both of which remained significantly higher than normal in long bones and vertebrae. These data arise important questions regarding the PTH suppression that is needed to produce skeletal benefits in the setting of CKD and whether PTH is an accurate biomarker of bone remodeling and mechanical properties.

In animal studies using calcitriol and paricalcitol in the $5 / 6$ th or $7 / 8$ th nephrectomy model, the results on bone have been mixed (table 6) [39-42]. Even in the presence of PTH suppression, only Jokihaara et al. [39] showed positive bone outcomes. In that study, 8-weekold animals underwent 5/6 nephrectomy and were treated with paricalcitol for 15 weeks. Levels of PTH suppression were similar to those in the current study, and femoral neck BMD and mechanical properties were higher than those in CKD animals and equivalent to those in normal animals. Yet, no beneficial effects were observed in BMD or mechanical properties at the femoral diaphysis (a site assessed in the current study). While variations in these models may explain some of the skeletal differ- ences, one possible explanation is that calcitriol has a preferential effect at certain skeletal sites. Although the femoral neck is a clinically relevant site, why it would be positively affected when the proximal tibia, femoral diaphysis and lumbar vertebra in the current study were not is unclear.

Despite the plethora of data showing the effectiveness of calcitriol and its analogs to suppress $\mathrm{PTH}$ in patients with advanced CKD [4, 43-46], far fewer clinical studies have examined the impact of these treatments on bone outcomes (table 7). As reviewed in the KDIGO CKDMBD guidelines, the evidence supporting a skeletal benefit of calcitriol or its analogs is weak [3]. In pediatric populations, calcitriol therapy has consistently shown effective suppression of bone turnover, though the associated suppression of PTH has been much more variable [4749]. Skeletal results in adult populations have been far less congruous. For example, 1 study in dialysis patients revealed increased BMD at the spine and the hip, even though PTH levels were not impacted [50]. Studies have described significant reductions in osteoblast surface/BS and Oc.S/BS in conjunction with a $73 \%$ decrease in PTH [51]. Conversely, other studies have shown no difference in these osteoblast/osteoclast parameters associated decrease in PTH $[52,53]$, although these studies were not designed to specifically study suppression of PTH to a given level. Despite some studies documenting changes in osteoblast and Oc.S measures, no study has documented differences/changes in the dynamic measures provided by fluorescent labeling, further adding to the obscurity. In summary, pediatric populations appear to be responsive to calcitriol and its analogs as they exhibit PTH suppression with associated changes in dynamic histology parameters. In adults, however, PTH changes are much less consistent, and the only histological changes observed are limited static parameters. These studies demonstrate the need for a fracture prevention clinical trial with calcitriol or its analogs.
Newman/Tian/Hammond/Wallace/ Brown/Chen/Moe/Allen 


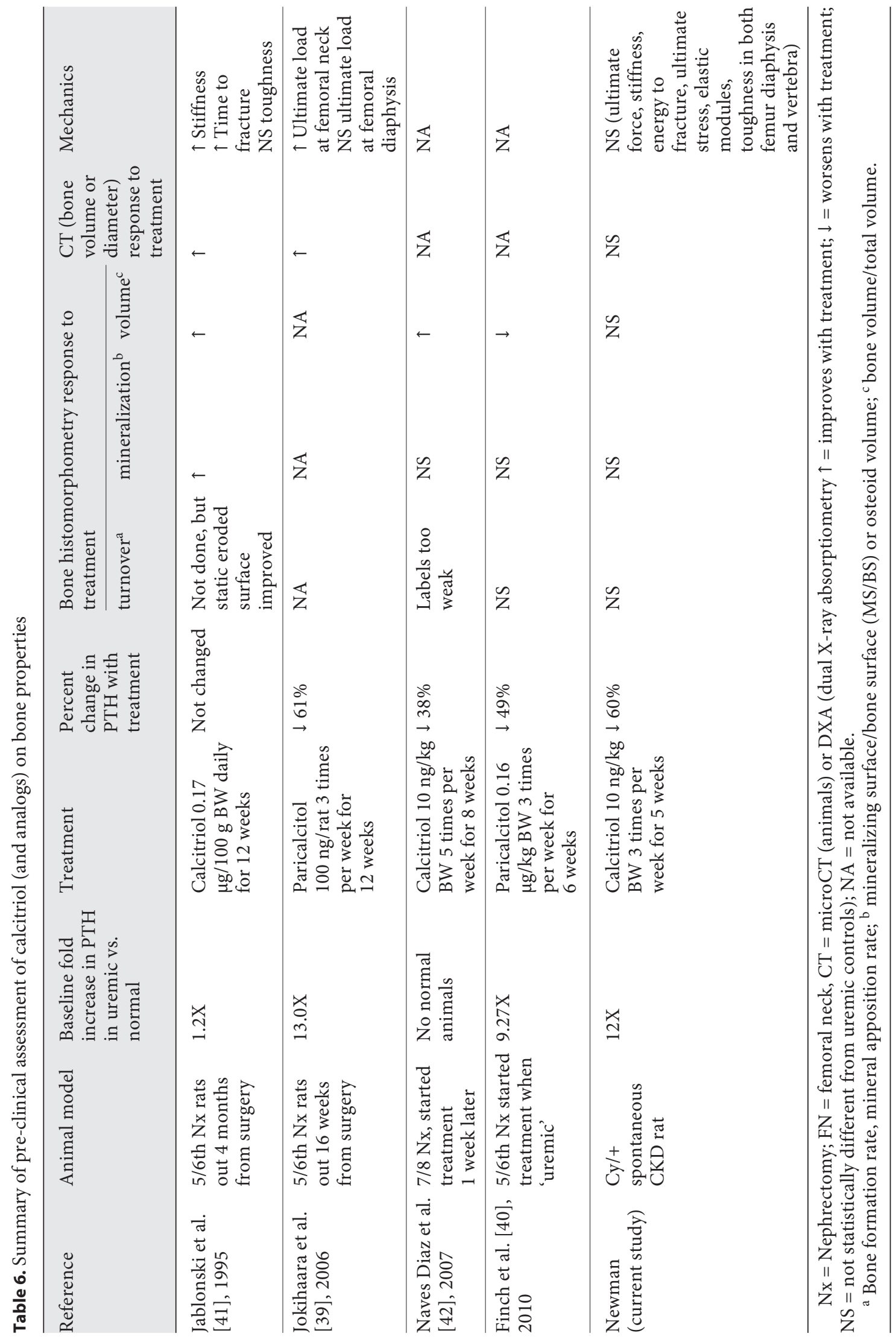




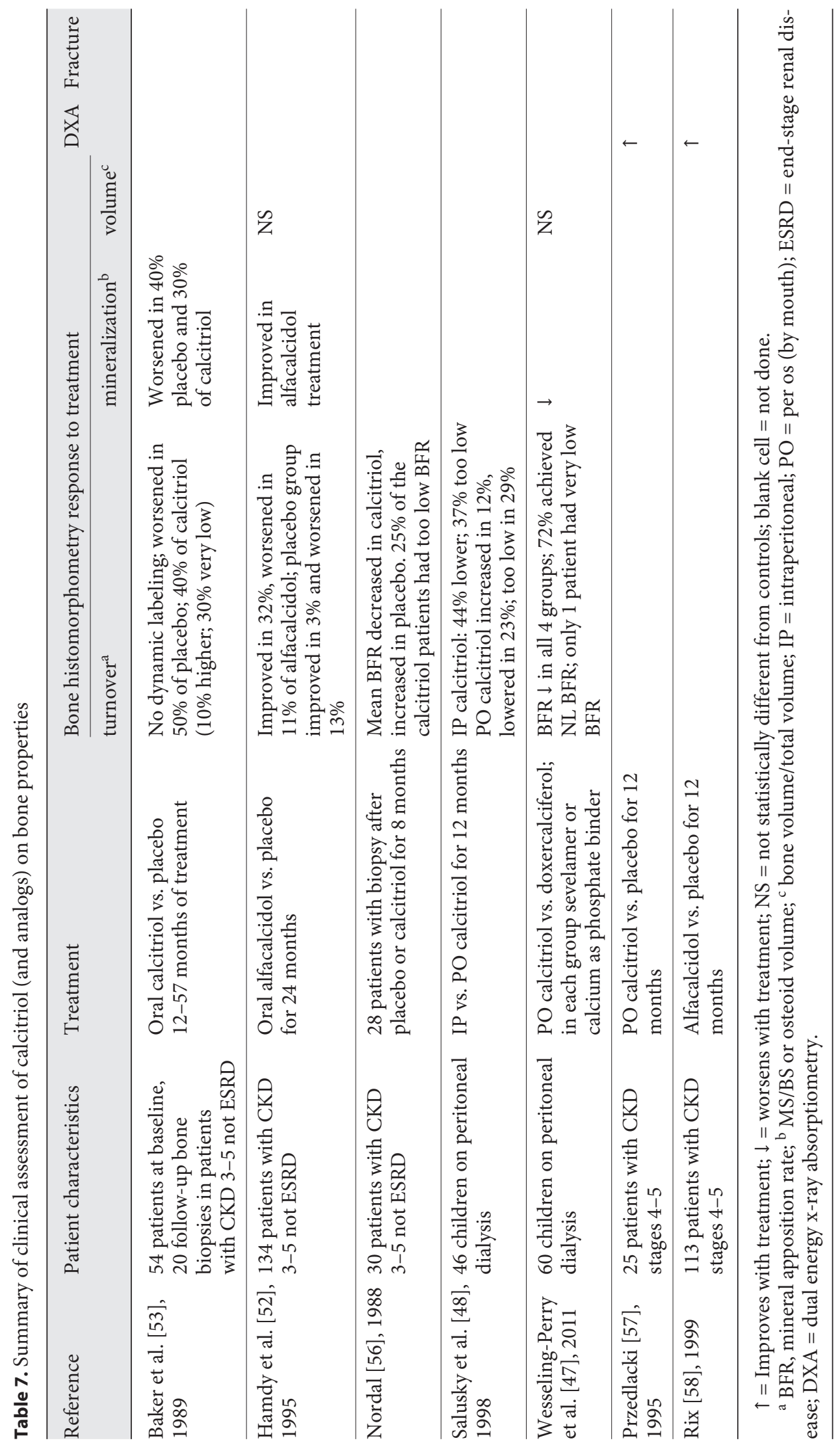


In the current study, dynamic measures were consistent with the human studies, though osteoclast number and percent surface remained at the level of untreated CKD animals. Most importantly, this study showed that calcitriol had no impact on any whole bone mechanical parameters or on those assessing bone quality. Unfortunately, none of these previous studies revealed clear relationships between bone remodeling and PTH suppression. In contrast, by using calcium in the same animal model, we did demonstrate efficacy in improving bone histology and CT [29]. However, it is unclear if this was a result of increased calcium or more aggressive suppression of PTH. Unfortunately, this approach also led to an exacerbation of arterial calcification. Taken together, these data lend support to previous suggestions that calcitriol may have a direct effect on bone independent of its effect on PTH [46]. Furthermore, because there have been no fracture trials using calcitriol in $\mathrm{CKD}$, the extension of its positive effects in patients with osteoporosis $[12,13]$ is simply unknown. The future of calcitriol therapy in patients with CKD requires fracture assessments for further evaluation. This raises the question of the goal of treatment with calcitriol and its analogs.

Our study has some limitations. We do not have baseline biochemistries or bone assessments. Previous work in this model shows that at 25 weeks, when we initiated treatment in the current study, the biochemistries are roughly comparable with respect to calcium and phosphorus, while BUN and $\mathrm{PTH}$ are already higher in $\mathrm{Cy} /+$ compared to normals $[16,55]$. We have not extensively studied the bone phenotype at 25 weeks of age. At 20 weeks of age, $\mathrm{Cy} /+$ animals already have higher osteoblast and Oc.S [55] without significant alterations in bone mass/geometry or mechanical properties. The current ex- periment was also limited in that only a single dose of calcitriol and a single duration of treatment were studied; it is possible that the outcomes would have differed with modification of either of these variables. Although we achieved our target goal of suppressing PTH by $~ 50 \%$, which matches the clinical goal of treatment with calcitriol, the levels of PTH in our model (12X normal) far exceed those of humans. Most clinical studies have excluded patients with very high PTH levels and thus it is possible that the degree of hyperparathyroidism or the severity of hyperphosphatemia could influence the efficacy of calcitriol on bone.

The current study demonstrated that calcitriol treatment, while efficacious in terms of PTH suppression in animals with CKD, did little to curb the detrimental effects of secondary hyperparathyroidism from CKD on the skeleton. This was demonstrated by its lack of effect on biochemical, histomorphometric and, most importantly, of all mechanical measures. Taken together, this indicates that a greater degree of PTH suppression may be required for efficacy in skeletal properties to occur in the setting of CKD. Alternatively, there may not be efficacy of calcitriol or its analogs on the skeleton. Fracture studies are greatly needed in this patient population.

\section{Acknowledgments}

This work was supported by the National Institutes of Health grants DL100093 (C.L.N.) and AR58005 (S.M.M.) and the Indiana Clinical and Translational Sciences Institute grant TR000162 (C.L.N.). The authors would like to thank Shannon Roy and D.M. Brown for technical assistance. They would also like to acknowledge the late Dr. Vincent H. Gattone II (1951-2013) for his instrumental work in developing and maintaining the animal model employed in the current study.

\section{References}

1 Levey AS, Eckardt KU, Tsukamoto Y, Levin A, Coresh J, Rossert J, De Zeeuw D, Hostetter TH, Lameire N, Eknoyan G: Definition and classification of chronic kidney disease: a position statement from kidney disease: improving global outcomes (KDIGO). Kidney Int 2005;67:2089-2100.

2 Levin A, Bakris GL, Molitch M, Smulders M, Tian J, Williams LA, Andress DL: Prevalence of abnormal serum vitamin D, PTH, calcium, and phosphorus in patients with chronic kidney disease: results of the study to evaluate early kidney disease. Kidney Int 2007;71:3138.

Calcitriol Fails to Improve Bone in CKD Animals
3 KDIGO: Clinical practice guidelines for the management of CKD-MBD. Kidney Int 2009;76:S1-S130.

4 Kandula P, Dobre M, Schold JD, Schreiber MJ Jr, Mehrotra R, Navaneethan SD: Vitamin D supplementation in chronic kidney disease: a systematic review and meta-analysis of observational studies and randomized controlled trials. Clin J Am Soc Nephrol 2011;6: $50-62$.

5 Coyne D, Acharya M, Qiu P, Abboud H, Batlle D, Rosansky S, Fadem S, Levine B, Williams L, Andress DL, Sprague SM: Paricalcitol capsule for the treatment of secondary hyper- parathyroidism in stages 3 and 4 CKD. Am J Kidney Dis 2006;47:263-276.

6 Coburn JW, Maung HM, Elangovan L, Germain MJ, Lindberg JS, Sprague SM, Williams ME, Bishop CW: Doxercalciferol safely suppresses PTH levels in patients with secondary hyperparathyroidism associated with chronic kidney disease stages 3 and 4. Am J Kidney Dis 2004;43:877-890.

7 Moorthi RN, Kandula P, Moe SM: Optimal vitamin $\mathrm{D}$, calcitriol, and vitamin $\mathrm{D}$ analog replacement in chronic kidney disease: to $\mathrm{D}$ or not to $\mathrm{D}$ : that is the question. Curr Opin Nephrol Hypertens 2011;20:354-359. 
8 Moe SM, Thadhani R: What have we learned about chronic kidney disease-mineral bone disorder from the EVOLVE and PRIMO trials? Curr Opin Nephrol Hypertens 2013;22: 651-655.

9 Moe S, Drueke T, Cunningham J, Goodman W, Martin K, Olgaard K, Ott S, Sprague S, Lameire N, Eknoyan G: Definition, evaluation, and classification of renal osteodystrophy: a position statement from kidney disease: improving global outcomes (KDIGO). Kidney Int 2006;69:1945-1953.

10 Goodman WG: The consequences of uncontrolled secondary hyperparathyroidism and its treatment in chronic kidney disease. Semin Dial 2004;17:209-216.

11 Martin KJ, Olgaard K, Coburn JW, Coen GM, Fukagawa M, Langman C, Malluche $\mathrm{HH}, \mathrm{Mc}-$ Carthy JT, Massry SG, Mehls O, Salusky IB, Silver JM, Smogorzewski MT, Slatopolsky EM, McCann L: Diagnosis, assessment, and treatment of bone turnover abnormalities in renal osteodystrophy. Am J Kidney Dis 2004; 43:558-565.

12 Bischoff-Ferrari HA, Willett WC, Wong JB, Giovannucci E, Dietrich T, Dawson-Hughes B: Fracture prevention with vitamin D supplementation: a meta-analysis of randomized controlled trials. JAMA 2005;293:2257-2264.

13 Peppone LJ, Hebl S, Purnell JQ, Reid ME, Rosier RN, Mustian KM, Palesh OG, Huston AJ, Ling MN, Morrow GR: The efficacy of calcitriol therapy in the management of bone loss and fractures: a qualitative review. Osteoporos Int 2010;21:1133-1149.

14 Allen MR, Chen NX, Gattone VH 2nd, Chen X, Carr AJ, LeBlanc P, Brown D, Moe SM: Skeletal effects of zoledronic acid in an animal model of chronic kidney disease. Osteoporos Int 2013;24:1471-1481.

15 Moe SM, Chen NX, Newman CL, Gattone $\mathrm{VH} 2$ 2nd, et al: A comparison of calcium to zoledronic acid for improvement of cortical bone in an animal model of CKD. J Bone Miner Res 2014;29:902-910.

16 Moe SM, Chen NX, Newman CL, Organ JM, Kneissel M, Kramer I, Gattone VH 2nd, Allen MR: Anti-sclerostin antibody treatment in a rat model of progressive renal osteodystrophy. J Bone Miner Res 2015;30:499-509.

17 Allen MR, Newman CL, Chen N, Granke M, Nyman JS, Moe SM: Changes in skeletal collagen cross-links and matrix hydration in high- and low-turnover chronic kidney disease. Osteoporos Int 2015;26:977-985.

18 Goodman WG, et al: Coronary-artery calcification in young adults with end-stage renal disease who are undergoing dialysis. $\mathrm{N}$ Engl J Med 2000;342:1478-1483.

19 Block GA, Raggi P, Bellasi A, Kooienga L, Spiegel DM: Mortality effect of coronary calcification and phosphate binder choice in incident hemodialysis patients. Kidney Int 2007;71:438-441.

20 Russo D, Miranda I, Ruocco C, Battaglia Y, Buonanno E, Manzi S, Russo L, Scafarto A, Andreucci VE: The progression of coronary artery calcification in predialysis patients on calcium carbonate or sevelamer. Kidney Int 2007;72:1255-1261.

21 Elder GJ: Calcium supplementation: lessons from the general population for chronic kidney disease and back. Curr Opin Nephrol Hypertens 2011;20:369-375.

22 West SL, Swan VJ, Jamal SA: Effects of calcium on cardiovascular events in patients with kidney disease and in a healthy population. Clin J Am Soc Nephrol 2010;5(suppl 1):S41S47.

23 Spence LA, Weaver CM: Calcium intake, vascular calcification, and vascular disease. Nutr Rev 2013;71:15-22.

24 Moe SM, Chen NX, Seifert MF, Sinders RM, Duan D, Chen X, Liang Y, Radcliff JS, White KE, Gattone VH 2nd: A rat model of chronic kidney disease-mineral bone disorder. Kidney Int 2009;75:176-184.

25 Nagao S, Morita M, Kugita M, Yoshihara D, et al: Polycystic kidney disease in Han:SPRD Cy rats is associated with elevated expression and mislocalization of SamCystin. Am J Physiol Renal Physiol 2010;299:F1078F1086.

26 Stagner EE, Bouvrette DJ, Cheng J, Bryda EC: The polycystic kidney disease-related proteins Biccl and SamCystin interact. Biochem Biophys Res Commun 2009;383:16-21.

27 Hoff S, et al: ANKS6 is a central component of a nephronophthisis module linking NEK8 to INVS and NPHP3. Nat Genet 2013;45: 951-956.

28 Allen MR, Chen NX, Gattone VH 2nd, Chen X, Carr AJ, LeBlanc P, Brown D, Moe SM: Skeletal effects of zoledronic acid in an animal model of chronic kidney disease. Osteoporos Int 2013;24:1471-1481.

29 Moe SM, Chen NX, Newman CL, Gattone VH 2nd, et al: A comparison of calcium to zoledronic acid for improvement of cortical bone in an animal model of CKD. J Bone Miner Res 2014;29:902-910.

30 Bouxsein ML, Boyd SK, Christiansen BA, Guldberg RE, Jepsen KJ, Muller R: Guidelines for assessment of bone microstructure in rodents using micro-computed tomography. J Bone Miner Res 2010;25:1468-1486.

31 Allen MR, Follet H, Khurana M, Sato M, Burr DB: Antiremodeling agents influence osteoblast activity differently in modeling and remodeling sites of canine rib. Calcif Tissue Int 2006; 79:255-261.

32 Allen MR, Erickson AM, Wang X, Burr DB, Martin RB, Hazelwood SJ: Morphological assessment of basic multicellular unit resorption parameters in dogs shows additional mechanisms of bisphosphonate effects on bone. Calcif Tissue Int 2010;86:67-71

33 Allen MR, Kubek DJ, Burr DB: Cancer treatment dosing regimens of zoledronic acid result in near-complete suppression of mandible intracortical bone remodeling in beagle dogs. J Bone Miner Res 2010;25:98-105

34 Dempster DW, Compston JE, Drezner MK, Glorieux FH, Kanis JA, Malluche H, Meunier
PJ, Ott SM, Recker RR, Parfitt AM: Standardized nomenclature, symbols, and units for bone histomorphometry: a 2012 update of the report of the ASBMR Histomorphometry Nomenclature Committee. J Bone Miner Res 2012;28:2-17.

35 Turner $\mathrm{CH}$, Burr DB: Experimental techniques for bone mechanics; in Cowin SC (ed): Bone Mechanics Handbook. Boca Raton, CRC Press, 2002.

36 Hogan HA, Ruhmann SP, Sampson HW: The mechanical properties of cancellous bone in the proximal tibia of ovariectomized rats. J Bone Miner Res 2000;15:284-292.

37 Bloomfield SA, Allen MR, Hogan HA, Delp MD: Site- and compartment-specific changes in bone with hindlimb unloading in mature adult rats. Bone 2002;31:149-157.

38 Hammond MA, Gallant MA, Burr DB, Wallace JM: Nanoscale changes in collagen are reflected in physical and mechanical properties of bone at the microscale in diabetic rats. Bone 2014;60:26-32.

39 Jokihaara J, Porsti I, Pajamaki I, Vuohelainen T, Jolma P, Koobi P, Kalliovalkama J, Niemela O, Kannus P, Sievanen H, Jarvinen TL: Paricalcitol [19-nor-1,25-(OH)2D2] in the treatment of experimental renal bone disease. J Bone Miner Res 2006;21:745-751.

40 Finch JL, Tokumoto M, Nakamura H, Yao W, Shahnazari M, Lane N, Slatopolsky E: Effect of paricalcitol and cinacalcet on serum phosphate, FGF-23, and bone in rats with chronic kidney disease. Am J Physiol Renal Physiol 2010;298:F1315-F1322.

41 Jablonski G, Mortensen BM, Klem KH, Mosekilde L, Danielsen CC, Gordeladze JO: Vitamin D3 analogs and salmon calcitonin partially reverse the development of renal osteodystrophy in rats. Calcif Tissue Int 1995; 57:385-391.

42 Naves Diaz M, Rodriguez Rodriguez A, Fernandez Martin JL, Serrano Arias M, Menendez Rodriguez P, Cannata Andia JB: Effects of estradiol, calcitriol and both treatments combined on bone histomorphometry in rats with chronic kidney disease and ovariectomy. Bone 2007;41:614-619.

43 Ott SM: Therapy for patients with CKD and low bone mineral density. Nat Rev Nephrol 2013;9:681-692.

44 Dogan E, Erkoc R, Sayarlioglu H, Soyoral Y, Dulger H: Effect of depot oral cholecalciferol treatment on secondary hyperparathyroidism in stage 3 and stage 4 chronic kidney diseases patients. Ren Fail 2008;30:407410

45 Chandra P, Binongo JN, Ziegler TR, Schlanger LE, Wang W, Someren JT, Tangpricha $\mathrm{V}$ : Cholecalciferol (vitamin D3) therapy and vitamin $\mathrm{D}$ insufficiency in patients with chronic kidney disease: a randomized controlled pilot study. Endocr Pract 2008;14:1017.

46 Coburn JW: Use of oral and parenteral calcitriol in the treatment of renal osteodystrophy. Kidney Int Suppl 1990;29:S54-S61. 
47 Wesseling-Perry K, Pereira RC, Sahney S, Gales B, Wang HJ, Elashoff R, Juppner H, Salusky IB: Calcitriol and doxercalciferol are equivalent in controlling bone turnover, suppressing parathyroid hormone, and increasing fibroblast growth factor-23 in secondary hyperparathyroidism. Kidney Int 2011;79: 112-119.

48 Salusky IB, Kuizon BD, Belin TR, Ramirez JA, Gales B, Segre GV, Goodman WG: Intermittent calcitriol therapy in secondary hyperparathyroidism: a comparison between oral and intraperitoneal administration. Kidney Int 1998;54:907-914.

49 Goodman WG, Ramirez JA, Belin TR, Chon Y, Gales B, Segre GV, Salusky IB: Development of adynamic bone in patients with secondary hyperparathyroidism after intermittent calcitriol therapy. Kidney Int 1994;46: 1160-1166.
50 Ruedin P, Rizzoli R, Slosman D, Leski M, Bonjour JP: Effects of oral calcitriol on bone mineral density in patients with end-stage renal failure. Kidney Int 1994;45:245-252.

51 Costa AF, dos Reis LM, Ribeiro MC, Moyses RM, Jorgetti V: Effects of calcitriol on parathyroid function and on bone remodelling in secondary hyperparathyroidism. Nephrol Dial Transplant 2003;18:743-749.

52 Hamdy NA, Kanis JA, Beneton MN, Brown CB, Juttmann JR, Jordans JG, Josse S, Meyrier A, Lins RL, Fairey IT: Effect of alfacalcidol on natural course of renal bone disease in mild to moderate renal failure. BMJ 1995;310:358-363.

53 Baker LR, Abrams SM, Roe CJ, Faugere MC, Fanti P, Subayti Y, Malluche HH: Early therapy of renal bone disease with calcitriol: a prospective double-blind study. Kidney Int Suppl 1989;27:S140-S142.

54 Newman CL, Creecy A, Granke M, Nyman JS, Tian N, Hammond MA, et al: Raloxifene improves skeletal properties in an animal model of cystic chronic kidney disease. Kidney Int 2015, Epub ahead of print.
55 Moe SM, Radcliffe JS, White KE, Gattone VH 2nd, Seifert MF, Chen X, et al: The pathophysiology of early-stage chronic kidney diseasemineral bone disorder (CKD-MBD) and response to phosphate binders in the rat. J Bone Miner Res 2011;26:2672-2681.

56 Nordal KP, Dahl E: Low dose calcitriol versus placebo in patients with predialysis chronic renal failure. J Clin Endocrinol Metab 1988;67:929-936.

57 Przedlacki J, Manelius J, Huttunen K: Bone mineral density evaluated by dual-energy $\mathrm{X}$ ray absorptiometry after one-year treatment with calcitriol started in the predialysis phase of chronic renal failure. Nephron 1995;69: 433-437.

58 Rix M, Andreassen H, Eskildsen P, Langdahl $\mathrm{B}$, Olgaard K: Bone mineral density and biochemical markers of bone turnover in patients with predialysis chronic renal failure. Kidney Int 1999;56:1084-1093. 